\title{
Entrepreneurship and Innovation Events during the COVID-19 Pandemic: The User Preferences of VirBELA Virtual 3D Platform at the SHIFT Event Organized in Finland
}

\author{
Jussi S. Jauhiainen ${ }^{1,2}$
}

Citation: Jauhiainen, J.S Entrepreneurship and Innovation Events during the COVID-19 Pandemic: The User Preferences of VirBELA Virtual 3D Platform at the SHIFT Event Organized in Finland. Sustainability 2021, 13, 3802. https:// doi.org/10.3390/su13073802

Academic Editor: Mi Jeong Kim

Received: 26 February 2021

Accepted: 25 March 2021

Published: 30 March 2021

Publisher's Note: MDPI stays neutral with regard to jurisdictional claims in published maps and institutional affiliations.

Copyright: (C) 2021 by the author. Licensee MDPI, Basel, Switzerland. This article is an open access article distributed under the terms and conditions of the Creative Commons Attribution (CC BY) license (https:// creativecommons.org/licenses/by/ $4.0 /)$.
1 Department of Geography and Geology, University of Turku, 20014 Turku, Finland; jusaja@utu.fi 2 Institute of Ecology and the Earth Sciences, University of Tartu, 50090 Tartu, Estonia

\begin{abstract}
The COVID-19 pandemic brought abrupt changes for international events that promote entrepreneurship and innovation. Usually, such events bring together thousands of participants to provide them with information about ongoing and emerging trends in their fields, to network with old and new colleagues and get ideas that can develop into innovations. In 2020, most such events were cancelled. Few events were organized virtually, that is without participants physically coming together. Compared with physical face-to-face events, virtual events reduce the travelrelated emissions and consumption, thereby supporting sustainability. This article studies the SHIFT entrepreneurship and innovation event held virtually in October 2020 and organized in Finland. For this article, the author gathered data about user preferences from surveying participants, speakers, presenters and organizers, almost all of whom were first-time users of VirBELA's 3D virtual platform. Furthermore, participant observation and interviews via avatars were conducted during the event. At the virtual event, $68 \%$ of respondents talked with former acquaintances, and $68 \%$ also talked with new acquaintances, and 53\% opinioned that using the virtual platform can support the emergence of innovations. Virtual entrepreneurship and innovation events have potential to support networking, novel ideas and thus innovations, but issues of trust and confidentiality arose concerns among some participants.
\end{abstract}

Keywords: 3D virtual platform; virtual reality; event; innovation; entrepreneurship; user experience; VirBELA; SHIFT; Finland

\section{Introduction}

Entrepreneurship, technology development and innovation events bring together key players to network, learn from others and acquire information about the current situation and emerging trends relevant to participants and their background communities or enterprises. These events became very popular during the 21st century to support innovation development in technology and enterprises. The largest events convened tens of thousands participants for several days in major cities around the world [1]. These events and others similar to them are short-term, temporary clusters that can positively impact the emergence and development of innovations [2,3]. At the same time, the events employ their organizers, bring financial gains (often to the city in which the event is held) and raise the profile of a sector, region or country, often internationally.

The COVID-19 pandemic spread globally from the spring of 2020 onward and especially affected the United States and European countries in which the largest international technology, innovation and entrepreneurship events have traditionally been organized. The immediate reaction to the pandemic was to put such events on hold and later either cancel or postpone them [4]. Some smaller events were organized between the first wave of the pandemic in the spring of 2020 and the second wave of in the autumn of 2020. These included hybrid events in which few participants were present locally, but the majority 
participated digitally online. Nevertheless, international events requiring the physical presence of many people were not possible.

Postponing and canceling events did not mean the need for business- and innovationrelated new information and acquaintances vanished. On the contrary, immediate necessities emerged on how to cope with and adapt to the new situation the pandemic and related restrictions caused. However, the usual ways to meet in the same place with thousands of people, exchange ideas with old and new acquaintances, learn about trends and traveling to another country could no longer occur. Therefore, broadcasting large-scale events online and conducting online meetings became solutions during the epidemic [2]. Presumably, the pandemic will create at least short-term challenges to people and enterprises in terms of interactions and how they work, learn, meet, travel and design, and also in communication between people [5].

One option to overcome the impossibility of meeting physically was to turn the event entirely virtual. During the 2010s, more than 100 digital three-dimensional (3D) platforms were developed for various kinds of events, hosting from ten to more than 10,000 participants simultaneously. The most commonly used platforms (in alphabetical order) were AltSpace, Breakroom, Engage, LearnBrite, MootUp, SpotMe, VirBELA and Virtway Events. Virtual events grew substantially during 2020 and the expected growth continued in 2021 [6].

In the 3D virtual platforms, reality is in a digital form. One key aspect of 3D virtual platforms is to enhance the feeling of "being-there," i.e., immersing the participant. A virtual platform may look similar to physical reality, or it can be without a physical equivalent in the material world. A highly immersive virtual environment (HIVE), in which a person can move in a digital environment, is visually more realistic than twodimensional maps and graphs or 3D images from one fixed position. The level of immersion and enhancing the participant's sense of spatial presence can be significantly increased by enhancing virtual reality capabilities, a stereoscopic perspective and the tracking on realworld movements in these 3D spatial representations. It also depends on the quality of the geospatial data used and the head mounted display's [HDM] technical characteristics [7]. There are HIVEs that represent geographic environments in a non-fictitious and nonabstract manner. This type of environment is called a geovisualization immersive virtual environment (GeoIVE) [8]. However, so far, most 3D platforms for commercial use and for holding meetings and events are far simpler virtual environments without in-depth HIVE dimensions and do not require or support the use of HDMs. With the advancement of information and communication technologies (ICTs), networks and devices, the 3D virtual platforms (simple HIVEs) have become quite easy and inexpensive to use. It is expected that the use of immersive virtual environments (even that of GeoIVEs) will substantially grow with the rapid advancing of VR technology and HDMs, availability of suitable game engine technology, lowering of quality HDM prices, enhancing of the visual (and even multi-sensorial) quality of HIVEs and faster inexpensive data transfer [7].

Currently, an Internet connection and a personal computer, tablet or smart phone are usually sufficient to engage with simple 3D virtual platforms. At the virtual event, the participant has an avatar, that is, a designed digital visual virtual character representing them when participating and interacting at the event. The result is that one does not need to travel, perhaps to another country, and a considerable amount of time and money to attend the event. One can easily spend USD 1000-2000 for attending a few days' event in a foreign country and a couple of days for traveling. Furthermore, hosting a physical event for a few thousand participants is expensive and results in carbon dioxide emissions and unnecessary consumption. The virtual and hybrid arrangements may signify a permanent change in event organization and implementation extending to the post-pandemic period [2,9-11].

This article is about the innovation supporting the potential of virtual 3D entrepreneurship and innovation events as evidenced by user experiences and practices. Such events (both traditional physical face-to-face events and current 3D digital events) are organized to promote networking and interaction among the attendees and rise their potential for 
innovations. Following Greenwald et al., the interaction can be novel because of with whom one can interact (e.g., remote people, such as those in a virtual event), or how one can interact (e.g., taking on a different physical appearance, such as an avatar in a virtual event) [12]. Furthermore, the environment can be novel because it is based on a physical place that only a few people can visit (an exclusive site), or because the experience it provides is inherently virtual (visiting a specific designed virtual event). More broadly, the article discusses digital-environment perspectives, in particular studying the processes connected to entrepreneurship [13].

Earlier research confirms that receiving new knowledge, sharing ideas through trustful networking as well as feeling trust in collaborative learning practices are important prerequisites to support the emergence of innovations. Direct face-to-face encounters and interactions have been recognized as important in building trust that requires significant face-to-face time [14]. This is not possible in virtual events in which the communication and information receiving takes place through and between avatars. Some authors claim that although virtual environments suit trust building in technical aspects, they are less suited to develop more enduring, deeper forms of trust [15]. Fostering and engaging participation is important when setting a new virtual event or transforming a face-to-face event into a virtual one. For more intense participation in a virtual event, the participants need to experience an inspiring, intrinsically motivating, involving and fun co-creation experience [16].

One result of the COVID-19 pandemic is that physical entrepreneurship and innovation events will continue digitally even when the pandemic restrictions are over, thus it is important to know about first time attendees' and less experienced users' experiences on such platforms. The event studied in this article is SHIFT, which was organized during the COVID-19 pandemic in October 2020 using the VirBELA 3D virtual platform [16]. VirBELA is a $3 \mathrm{D}$ virtual platform for distance working, distance learning and remotely organized events. The virtual platform was initially developed in 2012 and it has been designed further. In 2020, it had tens of thousands of monthly users who utilized it with personal computers, tablets and smart phones. On VirBELA's platform, the participant moves an avatar in a large digital event area, follows the event and communicates (verbally and by motion) with other avatars. The 3D digital event area includes buildings, open public outdoor and indoor spaces, and various special sites. In addition to ordinary participants, the speakers, enterprises, service and product presenters and organizers have avatars. Live and recorded video broadcasts are used with avatars or real people appearing on the screen. Virtual rooms have digitized features of regular events, such as information desks, PowerPoint presentations on the walls, etc. [17]. Besides VirBELA, there are also other rather similar 3D virtual platforms used for virtual events and conferences.

The two-day SHIFT international event gathers together participants involved in technology, business and innovation development. The event has been organized annually since 2016 in Turku, a town of 200,000 inhabitants in southwestern Finland. In 2019, one year before the pandemic, about 2000 participants, numerous speakers and enterprise presenters from Finland and abroad as well as local organizers gathered for the event. The first-time fully digital event in 2020 had several themes such as circular and fair data economy, strategic foresight, systems thinking, future literacy skills, digital hygge, resilient digitalization, democratic artificial intelligence (AI), decarbonization, etc. [18]. Every participant could learn about recent developments and network with each other, speakers and presenters via one's avatar during the event. This future- and results-oriented event also featured enterprise, organization and project presentations, various workshops and discussions.

Because of the COVID-19 pandemic, the two-day SHIFT 2020 event had to be organized without participants physically gathering in one place to attend. Just before starting the virtual event, the main organizer stated that "after all the time spent in traditional video meetings within the four walls, virtual SHIFT 2020 will feel like a truly real meeting platform. You are distant, but still genuinely together" (original interview in 
Finnish) [19]. As will be discussed, most participants were highly educated entrepreneurship and innovation-related professionals, many had attended previously physical entrepreneurship and innovation events (including SHIFT). At the same time, they were first-time users of a 3D virtual platform in an entrepreneurship and innovation event.

This article studies how event participants prepared and experienced using an avatar for interaction (meeting with people they knew and did not know) and the virtual platform for information, idea and knowledge sharing (experiencing the 3D digital platform as a trustful and secure site for receiving and sharing useful information for innovation development). These are key elements supporting the emergence of innovations. The potentiality of virtual 3D digital platforms for innovation development is discussed conceptually and empirically. The research question is: How do the virtual 3D entrepreneurship and innovation event participants act toward innovations as evidenced by the SHIFT event?

After this introduction, firstly, the model of innovation development process, i.e., how learning and experience transform into knowledge, novel ideas and eventually innovations, is conceptually elaborated. To highlight the setting of the contemporary virtual 3D platforms, it is discussed in the contexts of physical, virtual and extended realities and interactions between humans and machines. Particular attention is paid to the role of trustful and secure communication and interaction (networking) for innovation development. Secondly, the material and methods for the article are presented, namely the Internet survey conducted after the SHIFT event that two groups of people responded to: the ordinary participants and functional participants who had a specific role at the event, i.e., speakers, organizers and enterprise and organization presenters. In addition, at the event, participant observation was conducted using avatars, and interviews were held with participants since the author took part of this virtual event among ordinary participants. Thirdly, the results from survey, participant observation and interviews are presented, with a focus on the participants' practices with the avatar and their perceptions at the 3D virtual platform on issues such as trust, security and other important aspects in the innovation process. Finally, the article's discussion is presented.

\section{Innovation Development in Blended Environments}

An entrepreneurship and innovation event, even in 3D virtual platforms, can be an important support for the emergence of novel ideas and the consequent development of innovations. Such events gather people together with similar interests and motives to interact for business and innovation development [2,3]. Over the years, various scholars have researched physical face-to-face events, but less studies have been conducted on virtual platforms' opportunities and challenges in innovation processes. Scholars have begun to compare differences and similarities between physical and 3D virtual events in the emergence of innovations. A key topic studied has been the role of interaction for innovation development and how technologies support interaction at such events [16,20,21].

Learning and experiences influence a person's knowledge. To enhance understanding, the person needs to find a novel perspective on this existing knowledge. Because knowledge is not absolute and fixed, but open to progress, it is cognitive-constructive. The cognitive dimension means that a person's cognitive proximity facilitates the absorption of knowledge [22]. Knowledge entails cognitive categorizations, capabilities to interpret information, non-codified tacit skills and problem-solving capabilities [23]. An actor perceives the objectively available information in a system with their own cognitive model [24].

The constructive dimension means that knowledge is in relation to what is known at the moment. Experts (such as virtual conference attendees) construct knowledge from their personal experiences while interacting with their social constituencies (such as other conference attendees) in their niche of expertise [25]. The (potentially) new knowledge is validated among the peer groups that examine it and recognize if it improves the current understanding of the state-of-affairs, i.e., the existing knowledge. Suitable cognitive proximity (i.e., being able to understand each other, but not having exactly similar viewpoints) is 
important to progress novel knowledge. Being too similar with fairly identical knowledge bases and experiences inhibits divergent thinking [26].

Based on studies that explore the development of innovations in physical face-toface encounters and the emerging results of innovation development in virtual events, the following elaborates on a conceptual model for innovation development that takes into account various human-human, human-machine and machine-machine connections in physical, extended and virtual realities. In such a blended environment, combining elements from physical and virtual realms, innovations emerge from novel ideas based on knowledge that has developed from learning and experiences (Figure 1).

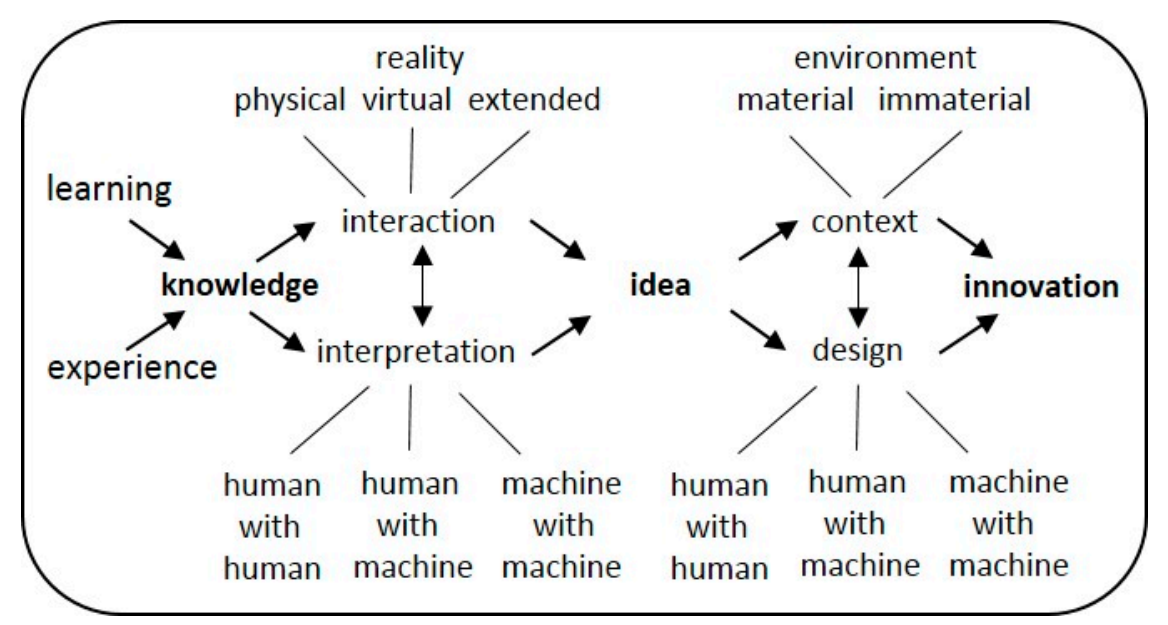

Figure 1. Model for innovation development.

\subsection{Generation of Ideas from Knowledge through Interpretation and Interaction}

Earlier, the interpretation of knowledge took place exclusively between humans or by one person alone examining the validity of existing knowledge. With technologies advancing, computers, ICTs and other machines have entered the interpretation process of existing knowledge. A connection between humans and machines facilitates the interpretation, speeding up the process with rapid calculations or browsing the databases. A more recent and rapidly developing scene is the validation and interpretation of knowledge through machine-to-machine learning. Machines alone are able to develop knowledge through machine learning and algorithms of artificial intelligence (AI) that simulates human intelligence in machines programmed to think like humans and mimic their actions and. This is taking place in various fields, including engineering and medicine, in which machines with AI-generated algorithms learn and perform better, for example, identifying and defining inconsistencies. Different human-to-human, human-to-machine and machine-to-machine combinations interpret existing knowledge differently. In the end, creativity-which is an interaction among aptitude, process, and environment through which an individual or group produces a novel and useful product within a social context [27] - is no longer humans' sole privilege being supported only by connections between humans.

In the process described above, new knowledge (relevant and peer-accepted interpretation against the existing knowledge) does not lead necessarily directly into an innovation. One needs to have a novel idea how this new knowledge will be applied. Interaction is crucial to develop knowledge into ideas. Before digitalization and widely distributed ICTs, interaction mostly took place only in the nearby physical reality in the material environment surrounding the stakeholders (Figure 1). In such material space, geographical proximity between stakeholders was seen as important, if not necessary, to facilitate the direct face-to-face communication and interaction between the key stakeholders [28]. Geographical proximity and immediacy between stakeholders helped create trust between them. Trust supports mutual interaction and the search for novelty in a process of which end results are not yet known. With mutual trust, stakeholders tend to interact and share 
information and knowledge more freely. This supports shared values, norms and attitudes, and lowers information asymmetries, risks of opportunism and transaction costs [29]. Such creation of trust is important in entrepreneurship and innovation events that physically bring together the participants into the same space. However, virtual event participants do not meet face-to-face. Earlier research suggests that trust is initially lower in computermediated communication, especially in teams aiming to achieve something together (such as ideas leading into an innovation). Trust solidifies when people have confidence in the reliability and integrity of other individuals and the communication site. A person in a virtual space can enhance their perceived trustworthiness by providing more information about their ability, benevolence, predictability, integrity and transparency [28]. This requires communication and interaction.

Interpretation and interaction are connected in the generation of ideas that happens both individually and in groups. People's character as individuals and their behavior in groups matter in this process. This interaction takes place in a communicative space connected to the material space in which there are interactive participants. However, this communicative-material space does not have to be contiguous. Geographical proximity between participants is not obligatory for interaction and communication in innovation processes [30]. Interaction can happen over distance, thus geographical proximity is neither a necessary nor sufficient condition for learning, although it facilitates interactive learning [31]. Earlier, phones supported interaction and later various ICTs did so, including immediate visual interaction over distance (via Skype, Zoom, Microsoft Teams, Google Meet, etc.). Such communicating stakeholders could see each other despite the geographical distance between them. Seeing each other means being able to observe better others' reactions that are key additional elements in creating trust [32]. However, challenges emerge when geographical proximity (i.e., sharing the same physical space while interacting between each other) becomes less common in innovation development due to ICTs. Creating trust becomes more challenging and elements of insecurity enter into interaction, for example, by not being able to recognize the immediate reactions of other people or by fearing that information will be leaked from digitally mediated communication and interaction.

More recent advances in digitalization make interaction possible outside purely physical reality. Augmented reality (AR; augmenting a real physical environment and world with digital 3D elements), mixed reality (MR; mixing 3D digital elements with physical bodies in a real physical environment), virtual reality (VR; experiencing a simulated environment and world through digital technological devices) and extended reality (XR; combining $\mathrm{AR}, \mathrm{MR}$ and VR into a unified blended experience that is more than a purely physical encounter) started to play a role in communication between stakeholders, and therefore in the processes where knowledge is converted into novel ideas through interpretation and interaction (Figure 1). Both material-physical and digital-virtual environments can be connected when communicative space develops into cognitive space in which the value of novel ideas is understood [30]. Digitalized realities and digitalization more broadly further relax the necessity of geographical proximity between stakeholders involved in interaction (Figure 1). Earlier studies indicate how VR can be utilized in many ways to enhance human interaction, cooperation and learning [12,33], including that of people's ability to generate ideas and innovate in virtual and physical realities. For groups that address a challenging topic, VR is better than physical reality in terms of achieving original ideas and how fluently these ideas develop. However, behavior, performance and idea generation in VR varies between individuals. Individuals with a propensity for higher risk taking are more creative in VR environments compared to those with a modest risk taking character. Furthermore, people with divergent thinking and mental flexibility seem to generate and process ideas better in VR compared with others [19]. However, potentially the role of immersive virtual environments is important, therefore one needs also to consider the potential differences between fictitious and more realistic HIVEs in interaction $[7,8]$. 


\subsection{Generating Innovations from Ideas through Contextualization and Design}

Third, as mentioned, various kinds of knowledge have become increasingly accessible through the Internet. However, not at all knowledge inspires ideas and not all ideas develop into innovations. Transforming an idea into innovation (a novel product, service, way to organize, etc.) takes place through the idea's contextualization and design, which are connected to each other (Figure 1). Placing a novel idea into a context can happen in a nearby physical environment (a country, a city or a place) or in an environment geographically distant from the person(s) who generated the idea. Digitalization makes possible contextualizing the idea also in the immaterial digital environment (e.g., digital space) without direct connection to the existing material physical environment.

Currently, various digitally mediated augmented, extended and virtual realities blend with the physical environment in numerous combinations. In such a blended environment, stakeholders are immersed into a simulated reality (a non-physical world) that can be beneficial for advancing ideas toward innovations. Such immersion has sensory-motoric (detecting affordances), cognitive (mental challenges), emotional (sensing a narrative arc) and spatial (perceptually convinced of being present) dimensions [34]. These influence the quality of an individual's experience in a blended immersive environment. This depends on the degree to which a person feels immersed and engaged with this environment. The feeling of being immersed into a more-than-real environment depends also on the quality of service provided in this blended environment [35]. The blended environment can support innovation development processes because it can offer experiences and immersion beyond those of the purely physical world, thus promoting and triggering novel perspectives and inspiration needed to achieve original ideas and how these ideas can be converted into innovations.

Besides contextualization, the idea needs to be designed before it can become an innovation (Figure 1). Visual, methodological and procedural design combine into an organizing principle that supports innovative initiatives. In fact, design has become the language of innovation [36]. In the design of ideas into innovations, various combinations exist of humans with humans, humans with machines and machines with machines. Design can take place in a process in which only humans are involved. Nowadays, it is more common that machines (with computer-assisted design programs, etc.) are utilized to assist humans in design activities. However, the designing of ideas into innovations will increasingly taking place also between "clever" AI-supported machines. Furthermore, developing ideas into innovation is not solely or even mostly based on supply, but the demand of innovation is becoming more important than purely the supply of it. Avatarbased innovations connect users in VR to innovation development processes [37].

\section{Materials and Methods}

The material derived from the SHIFT entrepreneurship and innovation event held on 27-28 October 2020, using the VirBELA virtual digital 3D platform. On both days, the program began at 10:30 a.m. local time and ended at 6:30 p.m. Main events for all participants were held in one place (the digital lecture hall). In addition, there were several sessions and workshops, some of which were conducted simultaneously in different locations in the virtual environment (different rooms in the main event building or other buildings; Figure 2). During the days, enterprises and other organizations presented their activities in a specific virtual expo hall. Throughout the event, avatars (participants, speakers, organizers, or presenters) could meet with each other without prior arrangements or planning in advance an exact time and place for a meeting. Both days' programs ended with a voluntary digital social event ("beach party") in the virtual beach area, featuring also livestream music. There, the avatars could talk, move around and even dance. 

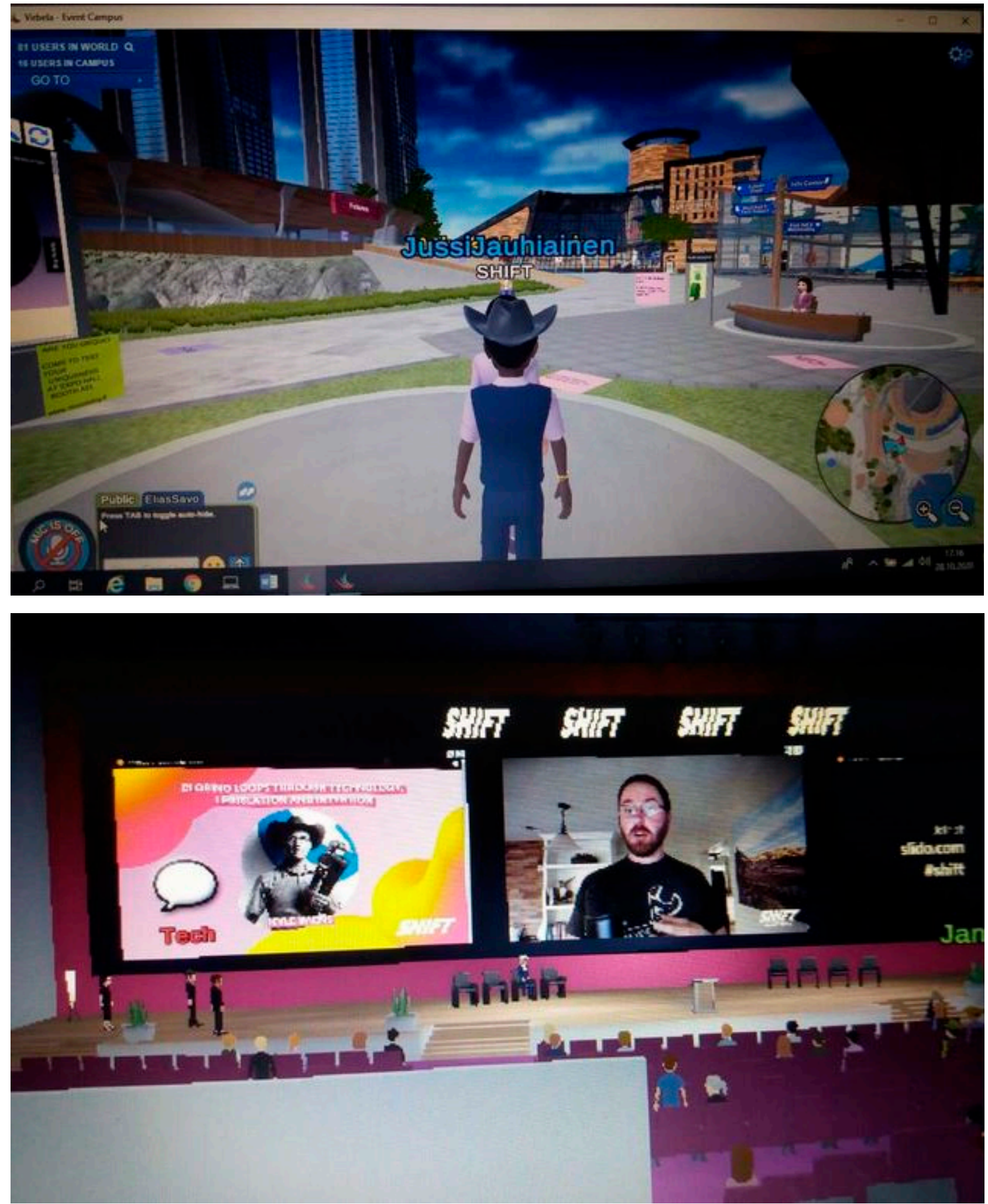

Figure 2. Outdoors and indoors of the SHIFT event on VirBELA 3D platform.

The first material consisted of a survey to the 2020 SHIFT event participants. Both functional participants (i.e., those having a specific function during the event such as organizer, speaker or presenter of an enterprise, organization or project) and ordinary participants (i.e., those without the earlier mentioned functions) were addressed. The fully anonymized questionnaire consisted of 14 questions about individual participants' basic 
backgrounds (i.e., gender, age, education, employment, place of residence, attendance at earlier SHIFT events, duty in the current SHIFT event, experiences about distance work and related tools, etc.) and 36 questions about their experiences regarding the 2020 SHIFT event and in particular about the digital 3D platform they used during the event. Of these questions, 47 were multiple choice, two were semi-open and one was open. The questionnaire topics were formulated based on earlier research issues on the topic. The form was prepared in the Webropol program, which allowed for the survey form with the questions to be sent via the Internet and responses received via the Internet so that they instantly entered a database. The questionnaire was sent six days after the event email to the event attendees and the responses were received 6-19 days after the event. Responding to the survey took about 7-10 min. Each responding participant formed one row in the SPSS database. The responses were analyzed with statistical methods including direct distribution of responses and cross tables. In this article, the respondents' viewpoints are discussed as one group, divided between ordinary respondents and functional participants, and along selected aspects regarding their backgrounds.

The second material consisted of the author's participatory observation via avatar in the event, interviews (talks) with 20 participants (3 functional and 17 ordinary participants) during the event and related notes written during and immediately after the event. In the beginning, the author registered to the event, downloaded the related program, created an avatar and took part in the event as an ordinary participant (i.e., not having a role of organizer, speaker or presenter during the event). The informal interviews (talks) lasted from a few minutes to $15 \mathrm{~min}$. The topics discussed focused on participants' experiences using the avatar, how they networked on this 3D digital platform during the event and if the person had any remarks on the innovation potential of such a 3D digital platform event, especially compared with a physical fact-to-face event. Notes were written down immediately during the interview as the author could attend the meeting at home and it was easy to write down the notes while using the avatar. After the event the notes were coded and organized into the above-mentioned themes (avatar-use experiences, networking, and innovation issues) and qualitative content analysis was applied to recognize and code the material into positive, neutral and negative aspects in these themes. These results were then reflected with the answers the functional and ordinary participants gave on these themes.

The participatory observation notes were also written down immediately during the two days event. These regarded the functionality in the event's organization, the attendance, mobility and communication of the avatars (i.e., the people behind them), and personal feelings of trust, security and comfort while using the avatar in different circumstances of the event (such as meeting and talking with new people or people known from before, or moving in and around the event site in formal and informal gatherings), and attending the functional events (such as lectures, seminars, workshops and expo meetings). After the event, the notes were organized and coded into the above-mentioned themes (trust, security and comfort/inconveniences) in different settings (i.e., formal/informal) and functional events (such as lectures, seminars, workshops and expo meetings). Additionally, this material was applied to qualitative content analysis to recognize and code positive, neutral and negative aspects in these themes. These results were then reflected with the answers the functional and ordinary participants gave on these themes.

The author's name was always visible above the avatar so that all individuals could see who was behind that avatar and with whom they talked during the event. The author was present during the whole period on both days of the event and attended the main activities (such as lectures, workshops, presentations, networking happenings, etc.) as well as moved around the site. It was the first time the author attended such an innovation and entrepreneurship event using a virtual 3D digital platform. However, before the SHIFT event, the author practiced using the avatar in VirBELA's Open Campus that is freely accessible and that was also used as the SHIFT event's virtual 3D platform. The notes from 
participatory observation and interviews/talks were analyzed after the event with thematic content analysis focused on the participants' behavior at the event and their avatar use.

In regard to the survey, the author asked the event organizers to send it to both ordinary and functional participants. It was easy to know the event's functional participants, i.e., those who attended the event while organizing it, those who were the invited speakers (their names appeared in the event program in advance) and those who presented their enterprise, organization or project activities (their sites were mentioned in the event program; however, the presenters' names were not indicated in advance). If interested and with time permitting, besides their functional duties, also functional participants had an opportunity to follow the event. Some functional participants (especially invited keynote speakers) were present only during their presentation, while others took part of the event at least for a few hours. There were 65 functional participants (plus/minus five persons) at the event. Of the functional participants, 23 anonymized respondents replied to the survey, making the average response rate $31 \%$ (29-33\%, depending on how many functional participants attended the event). The survey respondents covered well the entire population of the functional participants, i.e., having respondents from different roles in the event (organizer, keynote speaker or presenter) and both male and female as well as both Finnish and foreign origin respondents.

In regard to the survey sent to the ordinary participants, there were a few technical challenges. Without having the list of ordinary participants, the author had to rely on the event organizers to distribute the survey. However, for unknown reasons, the organizers did not have the list of ordinary participants. The organizers knew how many event tickets they had sold, but that number did not correspond with the actual number of ordinary participants. Furthermore, the organizer did not have all of the participants' emails because organizations collectively purchased many tickets without specifying their users.

The decision to organize a fully virtual SHIFT event instead of a physical face-to-face event came much later after many had already purchased tickets. If a ticket holder wanted to, they could postpone using their ticket to the event until 2021. Many organizations bought a certain number of tickets without specific names associated with them and did not control if all their tickets were used and who used them. Furthermore, the event was held during the COVID-19 pandemic, creating sometimes unexpected needs to cancel participation even if one had the ticket and an intention to use it. Therefore, it was impossible to know from the tickets sold how many ordinary participants attended the event. The technical platform provider could not reveal how many users were at the SHIFT event.

In the end, the organizers did not know how many ordinary participants attended the event and who they were. Based on observations, 150-250 avatars (i.e., individuals) usually attended the event at the same time, including the avatars of functional participants. About 50-60 avatars of functional participants were present at the event simultaneously, so the maximum number of ordinary participants simultaneously at the event was 200 or slightly less, though usually there were 100-150 at the same time. Ordinary participants came and went as they wished. Some of them were present at the event throughout the two days, but the majority were there for only a part of the event. From this, the rough estimation is that 230-400 ordinary participants attended the event. To separate true respondents from those who had not attended the event, the survey form asked whether the recipient had attended the SHIFT event. There were also a few other questions from which it became evident if the respondent really attended the event. However, as the organizers did not know the emails of all ordinary participants, they could not send the survey to all of them, rather perhaps only half of them. Due to these various challenges, of the ordinary participants, 23 responded to the survey (the estimated response rate is 6-10\% of all ordinary participants and $12-20 \%$ of those who received the survey). Despite the rather small number of survey respondents among ordinary participants, the respondents covered rather well the entire population of ordinary participants and their variation. The respondents' first and last names could be seen above their avatar during the event, thus 
indicating the participant's gender (if that was obvious from the first name). Besides gender, the author's random talks with around 20 participants revealed information about their age, professional background and earlier attendance to the SHIFT event. As discussed below, the share of female respondents is estimated to be slightly higher than what the actual situation was at the event. However, otherwise the ordinary participant respondents covered rather well the ordinary participant as a group.

\section{Results: User Experiences and Innovation Potential on the 3D Virtual Platform 4.1. Respondents' Backgrounds}

Of all respondents, 50\% were ordinary participants and 50\% were functional participants (Table 1). According to the program, 36 speakers had registered for the event, 21 of whom were from Finland and 15 from abroad. Four people acted as facilitators [8]. In addition, there were about 10-15 avatars on both days as representatives of companies, organizations and projects to illustrate their activities. Of functional participant respondents, $22 \%$ were organizers (22-28\% response rate of all organizers to the survey), $28 \%$ speakers (17\% response rate of all speakers to the survey) and 50\% presenters of an enterprise, organization or project (48-63\% response rate of all presenters to the survey).

Slightly over half $(57 \%)$ of the respondents were men and slightly less than half $(43 \%)$ were women. The gender divisions were rather similar among ordinary participant respondents (52\% men, $48 \%$ women) and functional participant respondents (57\% men, $43 \%$ women). The share of female respondents is estimated to be slightly higher than the actual situation at the event: women were close to $40 \%$ among functional and ordinary participants. Most respondents were middle-aged: 14\% less than 30 years old, 43\% $30-50$ years old and $43 \%$ over 50 years old. No major differences existed in ages between ordinary and functional participants (Table 1).

In general, respondents were highly educated (94\% had a university degree, and $26 \%$ held a PhD). All functional participants had completed a university degree. Of the ordinary participants $16 \%$ had not completed a university degree, but many were students (Table 1). A high level of education is expectable in an event targeted at professionals. The large share of people with a PhD is explainable by how in earlier years, SHIFT was organized physically in Turku, hosting several universities. Universities' staff took part in the event both prior to 2020 and in 2020.

The participants' main activities varied also among functional and ordinary respondents (Table 1). Of all respondents, 57\% were employed in the private sector (33\% as entrepreneurs and $24 \%$ as otherwise), $22 \%$ at a university or a university of applied sciences, $9 \%$ elsewhere in the public sector, $4 \%$ in other work positions and $7 \%$ were students. Compared with functional participants, the share of entrepreneurs was substantially higher among ordinary participants (48\% vs. $18 \%$ ) and subsequently much lower among those who had a job at a university (14\% vs. $27 \%$ ) or elsewhere in the public sector ( $5 \%$ vs. $14 \%$ ).

The physical site of the annual SHIFT event in 2016-2019 was the town of Turku in southwest Finland. Despite being an international event, the vast majority of participants came from Finland, and many from Turku and the surrounding area. Even though it was possible to attend the virtual 2020 SHIFT event from anywhere in the world, the overwhelming majority of respondents were from Finland (93\%; i.e., $7 \%$ from abroad) and in particular from Turku (73\%). Fewer (68\%) functional participant respondents lived in Turku because many invited speakers were from elsewhere. Of all respondents, 11\% were from Turku's surrounding area in southwest Finland and 11\% from elsewhere in Finland. On one hand, this indicates SHIFT's more regional framework. SLUSH, another entrepreneurship and innovation event held in Finland (in Helsinki), gathers a much wider audience both nationally and from other countries. More than 25,000 people attended the physical 2019 SLUSH event [1]. However, SLUSH was canceled in 2020 due to the COVID19 pandemic. On the other hand, because the 2020 SHIFT was organized for the first time as a virtual event, and because such a decision came rather late, no major marketing was done to gather participants from abroad, despite almost all presentations were in English. 
None of ordinary participant respondents were from abroad. Of functional participant respondents, $14 \%$ were from abroad mostly because of the invited speakers (Table 1 ).

Table 1. Respondent's backgrounds (total $n=44-46$, functional participant $n=22-23$ and ordinary participant $n=22-23)$.

\begin{tabular}{|c|c|c|c|}
\hline $\begin{array}{c}\text { Functional Participant } \\
\text { Background (\%) }\end{array}$ & & & \\
\hline Gender & $\begin{array}{l}\text { Male } \\
57\end{array}$ & $\begin{array}{l}\text { Female } \\
\quad 43\end{array}$ & \\
\hline Age & $\begin{array}{l}-29 \text { years } \\
23\end{array}$ & $\begin{array}{c}30-50 \text { years } \\
31\end{array}$ & $\begin{array}{l}\text { 51- years } \\
46\end{array}$ \\
\hline University education & $\begin{array}{c}\mathrm{PhD} \\
23\end{array}$ & $\begin{array}{c}\text { Other degree } \\
77\end{array}$ & $\begin{array}{c}\text { No degree } \\
0\end{array}$ \\
\hline Place of residence & $\begin{array}{c}\text { Turku } \\
68\end{array}$ & $\begin{array}{c}\text { Other Finland } \\
18\end{array}$ & $\begin{array}{c}\text { Abroad } \\
14\end{array}$ \\
\hline Earlier SHIFT attendance & $\begin{array}{l}\text { No } \\
27\end{array}$ & $\begin{array}{c}\text { Once } \\
37\end{array}$ & $\begin{array}{c}\text { Twice or more } \\
36\end{array}$ \\
\hline Time present at the event & $\begin{array}{c}>50 \% \\
18\end{array}$ & $\begin{array}{c}20-50 \% \\
50\end{array}$ & $\begin{array}{c}<20 \% \\
32\end{array}$ \\
\hline Distance work & $\begin{array}{c}\text { Fully } \\
52\end{array}$ & $\begin{array}{l}\text { Partly } \\
43\end{array}$ & $\begin{array}{c}\text { No } \\
5\end{array}$ \\
\hline Use of Zoom, MS Teams, etc. & $\begin{array}{l}\text { Yes } \\
91\end{array}$ & $\begin{array}{c}\text { No } \\
9\end{array}$ & \\
\hline $\begin{array}{c}\text { Ordinary Participant } \\
\text { Background (\%) }\end{array}$ & & & \\
\hline Gender & $\begin{array}{c}\text { Male } \\
52 \\
\end{array}$ & $\begin{array}{c}\text { Female } \\
48\end{array}$ & \\
\hline Age & $\begin{array}{l}-29 \text { years } \\
5\end{array}$ & $\begin{array}{c}30-50 \text { years } \\
45\end{array}$ & $\begin{array}{c}51-\text { years } \\
50\end{array}$ \\
\hline University education & $\begin{array}{c}\mathrm{PhD} \\
27\end{array}$ & $\begin{array}{c}\text { Other degree } \\
59\end{array}$ & $\begin{array}{l}\text { No degree } \\
14\end{array}$ \\
\hline Place of residence & $\begin{array}{c}\text { Turku } \\
73\end{array}$ & $\begin{array}{l}\text { Other Finland } \\
27\end{array}$ & $\begin{array}{c}\text { Abroad } \\
0\end{array}$ \\
\hline Earlier SHIFT attendance & $\begin{array}{c}\text { No } \\
50\end{array}$ & $\begin{array}{c}\text { Once } \\
23\end{array}$ & $\begin{array}{c}\text { Twice or more } \\
27\end{array}$ \\
\hline Time present at the event & $\begin{array}{c}>50 \% \\
27\end{array}$ & $\begin{array}{c}20-50 \% \\
59 \\
\end{array}$ & $\begin{array}{c}<20 \% \\
14\end{array}$ \\
\hline Distance work & $\begin{array}{c}\text { Fully } \\
54\end{array}$ & $\begin{array}{c}\text { Partly } \\
41\end{array}$ & $\begin{array}{c}\text { No } \\
5 \\
\end{array}$ \\
\hline Use of Zoom, MS Teams, etc. & $\begin{array}{c}\text { Yes } \\
100\end{array}$ & $\begin{array}{c}\text { No } \\
0\end{array}$ & \\
\hline
\end{tabular}

Of respondents, 39\% were first-time attendees of the SHIFT event in 2020, 30\% had attended it earlier once and 31\% had attended it between 2-4 times. Of functional participants, $27 \%$ attended for the first time and $50 \%$ for the ordinary participants (Table 1 ). The length of event attendance varied substantially among the participants and between functional and ordinary participants. Of all respondents, $24 \%$ participated only a little (less than a couple of hours) on both days and $23 \%$ for most of time on both days-ordinary participant respondents took part longer than functional ones. Of respondents, $11 \%$ did not attend the first day at all and $6 \%$ did not attend the second day at all. Of responded invited speakers, $67 \%$ attended the event for less than two hours. During the COVID-19 pandemic in 2020, many people's home space was converted into a working place. Of 
respondents, $80 \%$ attended the event at home (91\% of them as their work duties), $16 \%$ at their proper working place and $4 \%$ elsewhere (Table 1). Almost all respondents (96\%) worked remotely at least one day a week and the majority $(56 \%)$ worked throughout the whole five-day work week. Distance work requires using information and communication technologies. Of respondents, almost all used Zoom (91\%) or Microsoft Teams (83\%) (Table 1). During the COVID-19 pandemic, the distance work became common in Europe and North America, which increased the use of virtual platforms for communication [38].

\subsection{Interaction with Avatar at the 3D Virtual Platform}

Studies regarding innovation events have recognized key aspects of stakeholder interaction in innovation processes (see also Section 2). First of all, trustful interaction is important [16]. To create trust, people meet face-to-face in a physical event to judge and enhance one's reliability. Creating trust at initial stages is dependent on face-to-face interaction [39]. In a virtual platform, an exact face-to-face is not possible because people participate through avatars. This digital image is never an exact replica of the person is in the physical world, but its appearance can be both rather similar and something really different. One needs to study this "representation" of oneself through an avatar because it is used for social interaction, which is important in innovation processes [39].

Studies on users' avatar designs indicate that individuals tend to design an avatar to resemble oneself, especially essential features such as gender, skin color, etc. A good match between the avatar and one's real looks helps the user to identify with one's avatar [40]. This in turn helps the user to function authentically and well through the avatar [41]. In designing avatars, users often idealize and complement their own physical features by adding to it details they lack in their physical body. The avatar might appear with their preferred hair color and style, color of eyes, etc., and with specific clothing and accessories [42]. An avatar is an extension of one's sense of self and a message about oneself to other people [43]. A business look creates an image of a business-oriented person and a provocative look raises attention, though not necessarily a positive one.

As mentioned, the basic initial procedures of the VirBELA digital 3D virtual platform at the 2020 SHIFT event were similar to many other virtual platforms. In the beginning, to attend the event, participants downloaded a free virtual platform software VirBELA (by Virbela, Bellingham, Washington, USA), opened the digital event platform (in the case for SHIFT) on the device (computer, tablet, smartphone) designed an avatar and started to attend the event by moving the avatar in the site to follow the activities and, if one wished, to interact with other participants. As in the physical event, the 3D virtual platform consisted of open and enclosed spaces, buildings and rooms structures that enabled and directed interaction [19].

On the VirBELA platform, the participants selected the avatar's gender (male or female) that is visually easy to distinguish. In regard to age, one can modify the avatar's physical features, for example, by choosing the hair color and style. The ethnicity can be designed by selecting skin color and eyes. Additionally, the avatar's "personality" can be completed with a fairly wide clothing selection. This includes different types and colored headwear and shoes, shorter and longer pants and skirts, shirts and jackets, as well as a variety of accessories (watches, jewelry, eyeglasses, sunglasses, etc.). Furthermore, the avatar's look and clothing can be easily and quickly changed at any time. However, the avatar does not have to necessarily resemble the user's real bodily appearance, clothing or behavior. Nevertheless, the first name and surname of the avatar's registered user always appear above one's avatar.

Of respondents, almost all ( $89 \%$ ) designed one's avatar to resemble oneself ( $50 \%$ much, $39 \%$ somewhat) and very few (9\%) designed it without reference to their physical looks. A lot of research has been published over the past decades on how one's physical appearance and clothing impact others' opinion about the person in meetings and events. Appearance influences a person's credibility and possibilities for interaction and networking [44]. However, the studies on the impact of an avatar's clothing and visual appearance have 
scarcely been studied so far. In SHIFT, almost all participants attended their first virtual $3 \mathrm{D}$ event, therefore they did not have experience of the potential impact an avatar's looks could have. In fact, $63 \%$ of the respondents could not answer whether the appearance of one's avatar influenced how other people perceived the person behind the avatar $(29 \%$ argued that their avatar's appearance had no effect on others' attitudes toward them and only $7 \%$ were certain that the appearance had either a positive or negative effect). Only a few were very confident that the avatar's appearance had an impact. This is different from what people consider in physical events in regard to a person's clothing and behavior.

Compared with a physical event, in a virtual event one has no proper need to change the avatar's clothing because it remains clean and in good shape. However, for the 2020 SHIFT event, the activities ranged from formal meetings and lectures to informal afterwork parties. Of respondents, $23 \%$ edited their avatar during the two-day event, but the remaining $77 \%$ did not edit it at all. Some avatars were dressed formal during the lectures and casual in the informal organized gatherings, such as the evening beach party, but most had the same look throughout the event. In the end, the avatars' general appearances at the virtual 2020 SHIFT event were quite like the looks in physical face-to-face events in Finland. Most avatars had a semiformal or slightly casual appearance as is common in physical entrepreneurship and innovation events. The virtual environment was of course COVID-19 free so avatars did not wear facemasks, which would have been the case of a physical face-to-face event during the pandemic. In general, the avatars' looks resembled people in their 30s or early 40 s, i.e., slightly younger than the avatars' users who were mostly in their late $40 \mathrm{~s}$ or $50 \mathrm{~s}$. This confirms earlier studies that suggest a slight idealization in the design of one's avatar [43]. There were hardly any avatars with provocative clothing or strong mixtures of colors in clothing.

Interaction and networking are crucial elements in entrepreneurship innovation events and important in innovation development processes. In the physical event, interaction takes place rather naturally in face-to-face. However, in virtual events interaction happens (if it does at all) digitally mediated through avatars. Common to virtual platforms, avatars communicate between each other as a form of "avatar-to-avatar" interaction. Networking in an event requires mobility and meeting people. During the virtual event, it was rather simple to move the avatar from place to place with the device's (such as a laptop computer) arrow keys and space bar. The avatar's movement, turning, standing and sitting resembled that of a real person, though caricatured. Differently, the avatar could move instantly (in a fraction of a second) from one room or building to another or from inside the building to outside and back. Of respondents, $68 \%$ thought that using avatar was pleasant while $18 \%$ disagreed on this ( $14 \%$ could not say).

In physical face-to-face entrepreneurship and innovation events, experienced participants know that the programs contain relevant information, but it is very important to network with other attendees and speakers-both with those one knows and those new (potentially) interesting acquaintances. In physical events, formal and informal programs facilitate the flow of information and meetings. Thus, it is relevant to know if participants of a virtual 3D event achieved support for innovation development through networking and interaction.

During many formal activities at the SHIFT event (such as keynote speakers' lectures, panel discussions, etc.) avatars were expected to behave properly, sit quietly and follow the presentations. If one's avatar stood in front of sitting avatars or talked during a presentation, an organizer's avatar came over to suggest to sit down or to continue the talk outside the lecture room, as it would have happened in a physical face-to-face event. Besides just moving, one could also start to talk (through an integrated microphone) with other avatars or just hang around. Of functional participant respondents and of ordinary participant respondents, $59 \%$ and $74 \%$, respectively, mentioned that during the event they moved the avatar at times without a goal as it is done in physical face-to-face events. Many used the avatar to listen to music, take part in social activities during the event's organized free-time activities or to stroll around the virtual platform. An avatar could run on the grass, kick 
a football, dance or take a motorboat ride, among many other activities. Dangerous or socially questionable activities were not possible such as fighting with other avatars or jumping down from a balcony or cliff. An avatar could bounce against another avatar (accidentally or on purpose), but the avatar went through the other without any strange effect or sound. At the SHIFT event, avatars mostly followed the usual social conventions of physical face-to-face events. Avatars sat quietly and no upsetting interventions appeared. In more relaxed occasions, such as in the organized virtual beach party after the official program, some avatars danced, jumped or moved around more actively, as expected. In all, avatars were used not only for functional work-related aspects, but also social gatherings.

Interaction and social networking are crucial in business and innovation events. A participant may wish to acquire information about relevant ongoing and emerging trends, to network socially and obtain novel supportive ideas for innovation processes. Usually participants get (re)acquainted in advance both with people they know and those they do not know. At the SHIFT event, no one knew all of its 60-70 functional participants and $230-400$ ordinary participants. The issue was then if the event provided potentially interesting contacts for participants, if participants had time and opportunity for these contacts and if the virtual platform technically allowed this social networking. Every one at the SHIFT event could meet and talk via avatars. No one was familiar with the avatars' looks, thus recognizing people face-to-face was not possible as in a physical event. However, one could recognize a person's name above the avatar.

On the SHIFT virtual platform, $68 \%$ of respondents talked (through an integrated microphone) via one's own avatar to an avatar of a former acquaintance (32\% did not talk) and also $68 \%$ talked to an avatar of a new acquaintance ( $5 \%$ cannot say, $27 \%$ disagreed to have talked) (Table 2). Despite such networking, a minority (37\%) agreed to have received useful work-related contacts (54\% disagreed on this, $9 \%$ did not know) during the event and very few (14\%) obtained useful social contacts (68\% disagreed on this, $18 \%$ did not know). The respondents' focus at the event was thus on networking, i.e., maintaining old and obtaining new potentially relevant work-related relationships. A clear majority of respondents (57\%) achieved useful information at the event (27\% disagreed on this, $16 \%$ did not know). The view on this did not differ between the first time and experienced SHIFT event attendees.

Being a new 3D digital platform user and related avatar in an entrepreneurship and innovation event did not prevent participants from networking. It is thus useful to inspect more precise user experiences. Of respondents, $76 \%$ expressed that interaction in the virtual platform was for them more difficult than in a face-to-face event (12\% disagreed on this, $12 \%$ did not know). All respondents were rather unexperienced virtual platform users. Only a minority $(25 \%)$ of respondents agreed that at the event it was easy to get in contact with specific individuals ( $45 \%$ did not agree, $30 \%$ did not know). However, this might have been due to the unavailability of a suitable person and not related to technical features of the platform or avatar.

There were differences in participants' networking. Of more experienced participants, i.e., those who had attended the SHIFT event before 2020, $74 \%$ talked via avatar with a former acquaintance and $78 \%$ with a new person. Of less experienced participants (having not attended SHIFT earlier), fewer (56\%) talked via avatar with a former acquaintance or with a new person (57\%). The experienced participants used the event more efficiently for networking. Furthermore, those with a specific task at the event (functional participants) more likely were in contact with new people. This was probably due to many participants ${ }^{\prime}$ interest to establish contact with keynote speakers, presenters and organizers. Of functional participant respondents, $77 \%$ talked via avatar with a new person and fewer (59\%) ordinary participant respondents did so. 
Table 2. Respondents' views on innovation related issues at the $3 \mathrm{D}$ virtual platform (total $n=44$, functional participants $n=22$ and ordinary participants $n=22$ ).

\begin{tabular}{|c|c|c|c|}
\hline Functional Participant (\%) & Agree & Don't Know & Disagree \\
\hline $\begin{array}{c}\text { Talked to a former acquaintance at the 3D } \\
\text { virtual platform }\end{array}$ & 77 & 9 & 14 \\
\hline Talked to a new person at the 3D virtual platform & 77 & 0 & 23 \\
\hline $\begin{array}{l}\text { Emergence of innovations can be supported by the } \\
\text { 3D virtual platform }\end{array}$ & 59 & 27 & 14 \\
\hline $\begin{array}{c}\text { Possibility for trustful relationships at the 3D } \\
\text { virtual platform }\end{array}$ & 50 & 27 & 23 \\
\hline Security risks at the 3D virtual platform & 64 & 18 & 18 \\
\hline $\begin{array}{l}\text { Wish in the future to participate to an } \\
\text { entrepreneurship and innovation event at the 3D } \\
\text { virtual platform }\end{array}$ & 73 & 18 & 18 \\
\hline Recommend the use of the 3D virtual platform & 73 & 18 & 18 \\
\hline Ordinary Participant (\%) & Agree & Don't Know & Disagree \\
\hline $\begin{array}{c}\text { Talked to a former acquaintance at the 3D } \\
\text { virtual platform }\end{array}$ & 59 & 0 & 41 \\
\hline Talked to a new person at the 3D virtual platform & 59 & 0 & 41 \\
\hline $\begin{array}{c}\text { Emergence of innovations can be supported by the } \\
\text { 3D virtual platform }\end{array}$ & 48 & 3 & 49 \\
\hline $\begin{array}{c}\text { Possibility for trustful relationships at the 3D } \\
\text { virtual platform }\end{array}$ & 29 & 62 & 9 \\
\hline Security risks at the 3D virtual platform & 24 & 43 & 33 \\
\hline $\begin{array}{l}\text { Wish in the future to participate to an } \\
\text { entrepreneurship and innovation event at the 3D } \\
\text { virtual platform }\end{array}$ & 77 & 9 & 14 \\
\hline Recommend the use of the 3D virtual platform & 73 & 18 & 9 \\
\hline
\end{tabular}

Of respondents who expressed disappointment on the virtual platform use, $64 \%$ talked via avatar with a new person ( $36 \%$ did not or did not know). This was only slightly less than the average among all respondents. Of those who opinioned that using the avatar was not pleasant (or who were not sure about it), 62\% talked with a new person ( $38 \%$ did not or did not know). Of those who thought that talking in a virtual platform was a larger security risk than talking face-to-face or were not sure about this issue, even slightly fewer $(58 \%)$ talked via avatar with a new person ( $42 \%$ did not talk or did not know). In all, those having or perceiving technology-related concerns about the virtual platform were slightly less active in networking and getting in touch with new people during this virtual event. In the end, the respondents' viewpoints varied substantially whether the interaction on the $3 \mathrm{D}$ virtual platform was at least as good as an interaction on Zoom, Microsoft Teams and similar interaction tools (44\% agreed on this, $16 \%$ did not know and $40 \%$ disagreed on this). Of those who perceived the interaction at the $3 \mathrm{D}$ virtual platform to be at least as good as an interaction on the abovementioned interaction tools, more were female, 30-50 years old and actively networking participants. They more often thought that a virtual platform could support the emergence of innovations and that trustful relationships could be created on a virtual platform. Therefore, they more often recommended others to take part in innovation events held at virtual platforms.

"Face-to-face" meetings between avatars had some challenges because the avatar could not express physically any detailed feelings. Bodily and facial expressions are important in face-to-face contacts to support one's intentions and to judge better the messages [45]. An avatar could perform basic expressions such as clapping hands, making 
a gesture of thinking, indicating being amazed with hand or jumping from excitement, but these are far from the fine-tuned expressions of living persons. Based on the author's observations, very few participants expressed any emotions through avatars. Initiating a conversation, i.e., approaching other avatars, was a bit more reserved than in a faceto-face meeting. However, avatars' micro-gestures are very important. With expressions in the virtual 3D platforms, one gives and receives complementary social information in interaction [46]. Earlier studies indicate that a particularly friendly looking and smiling avatar brings a positive feeling to other participants. Through such a happy and confidentlooking avatar, one can deliver the message better, even if other participants do not always consciously notice such looks of avatar [47]. An avatar's face and micro-gestures are of great importance for successful interaction and forming a positive image about oneself in a virtual space. In addition, one could (try to) express emotions through the selection of words and voice tone when conversing with another avatar.

\subsection{Trust, Security and Innovation Potential at the 3D Virtual Platform}

As discussed above, entrepreneurship and innovation events can be helpful for networking that supports novel ideas that can eventually turn into innovations. In all, 55\% of respondents expressed that a virtual platform could support the emergence of innovations. However, a large share (33\%) did not know how to comment on that issue, but nevertheless rather few (12\%) disagreed on it (Table 2). Those participants who opinioned more positively about the 3D virtual platform's potential for emergence of innovations were university employees, had tried the VirBela platform before the SHIFT event, and were more active networkers at the virtual SHIFT event. They thought more often that trustful relationships could be created on the virtual platform and perceived interaction there to be at least as good as in Zoom or Microsoft Teams. Therefore, a larger share of them recommended other people to take part in innovation events held at virtual platforms.

Trust and security are key aspects in interaction that can eventually lead into an innovation, as explained in the innovation process model in Section 2 and by many scholars $[26,36]$. The respondents' opinions varied a lot on whether one can create trustful relationships at a virtual platform (40\% agreed, $44 \%$ did not know and 16\% disagreed; Table 2). Most participants had not yet had experience with such platforms and therefore many were uncertain. Only time will tell if networking and new acquaintances gained on the virtual platform will be trustful. One can perceive that talking on a virtual 3D platform might be riskier than at a face-to-face event. Someone might record conversations at the digital event and other avatars around may overhear a discussion between two avatars. Based on the author's experiences during the SHIFT event, it was possible to hear conversations very clearly if one's avatar was reasonably close to other discussing avatars. Those avatars did not notice that another avatar was listening to them. Of the respondents, $54 \%$ disagreed with the statement: "It is possible to share confidential information in virtual platform" (9\% did not know, 37\% agreed). Furthermore, $47 \%$ of respondents opinioned that discussion via avatars on a virtual platform bears more security risks than a face-to-face discussion (30\% did not know, 23\% disagreed on this; Table 2). Those at the SHIFT event who did not interact verbally with another avatar (i.e., the person behind it) were more concerned about the security risks than those who talked via avatar with another avatar ( $47 \%$ vs. $40 \%$ agreed on risks, $47 \%$ vs. $31 \%$ did not know, $6 \%$ vs. $29 \%$ disagreed on risks). Perceived security risks might prevent participants from talking to each other on a virtual platform. Of respondents who felt that the virtual platform use was a disappointment, a larger share perceived such security risks (46\% agreed, 39\% did not know, 15\% disagreed). Earlier studies indicate that those who have a lower propensity for higher risk taking are less creative in VR environments compared to those with a higher risk-taking character [18]. Being worried about security and confidentiality might prevent creative opportunities of VR platforms for many.

Despite almost half of respondents had reservations (such as confidentiality and security) regarding the 3D virtual platform, after visiting their first entrepreneurship and 
innovation event using such a platform, a large share of respondents felt positively about the 3D virtual platform use (in this case the VirBELA platform). The SHIFT virtual platform and its connections functioned well enough according to $80 \%$ (18\% did not know, $2 \%$ disagreed). Of the respondents, $74 \%$ said they would like to participate in innovation events on a similar virtual platform in the future (15\% did not know, $11 \%$ disagreed; Table 2). Almost the same amount $(72 \%)$ would recommend others to participate in innovation events on a virtual 3D platform (19\% did not know, $9 \%$ disagreed; Table 2). Of disappointed users, slightly fewer $(64 \%)$ would recommend it. Logically, of those who were not disappointed of the virtual platform use, substantially more (83\%) recommended its use. Within a couple of weeks after the SHIFT event, almost all respondents $(88 \%)$ had shared their experiences of the virtual platform use. That was substantially more than sharing their views about the event content with others (61\%). This was probably due to the novel experience of using such a platform.

\section{Discussion}

The constraints due to the COVID-19 pandemic in 2020 made necessary canceling a large number of entrepreneurship, technology, enterprise and innovation events. Such events are considered important for innovation development, i.e., that the attendees obtain new information, ideas and access to networks that support the emergence of innovations. As an alternative, some previously face-to-face events were organized through virtual 3D platforms. Their popularity increases and extends through the post-pandemic period, not least due to organizers', speakers' and participants' saving time and money. Furthermore, these virtual events are environmentally more sustainable by reducing carbon emissions and consumption that would occur in a physical meeting. The potential and challenges of virtual 3D entrepreneurship and innovation events for supporting innovations need to be scrutinized. It is crucial to know both first-time and more experienced users' experiences to enhance the virtual 3D platforms' potential for innovation development. The blended environment combining material and virtual elements has potential to push innovation processes, offering experiences beyond those of the purely physical world. The use of 3D platforms for supporting innovation and entrepreneurship will become even more important in the recovery from the COVID-19 pandemic - a topic that has not yet been addressed in-depth by scholars [5,48].

This article studied the two-day entrepreneurship and innovation event SHIFT organized during the COVID-19 pandemic in October 2020, using the VirBELA 3D virtual platform. This article focused on elements that precede innovations and novel ideas, i.e., event participants being able to network and interact with former and new acquaintances at the event and feeling secure and confident in the interactive environment. Most participants were professionals, almost all with a university degree and without prior experience of attending an entrepreneurship and innovation event on a 3D virtual platform, though many had attended similar events as physical gatherings. Therefore, most had enough cognitive proximity for developing learning toward novel ideas and innovations as such a condition has been found crucial in earlier studies [23,24,30].

The answer to the article's main research question is that the SHIFT virtual 3D entrepreneurship and innovation event participants acted toward innovations quite much like they would at a physical event, i.e., they followed or at least tried to follow the presentations, received new information and networked with other participants. Four out of five respondents felt that the virtual platform and Internet connection worked technically well enough. The majority of respondents opinioned that a virtual platform could support the emergence of innovations. Another key research question regarded the users' practices with avatars. The event participants prepared and experienced the use of the avatar for interaction (meeting with people they knew and did not know), and more than two out of three found the avatar use pleasant. The vast majority tried to shape their avatar to look like they did in the physical world, which is a practice that earlier studies $[43,45]$ have also found out. A further question was about the participants' feeling of trust and 
security in networking and interactions, which are important in entrepreneurship and innovation events, in search for potential innovations. On the studied virtual platform, rather many participants had concerns about confidentiality, security and the trustworthiness of networking through avatars. Furthermore, the participants lacked routines expressing immediate feelings via avatar. Such expression of feelings via avatar has been found important in earlier studies about the role of the avatar [44], thus the creation and perception of trust were challenged at the SHIFT event partly due to these technical details. Reserved and less experienced $3 \mathrm{D}$ virtual platform users were more reluctant to interact, and thus did not advance the innovation process. Limited networking and interaction (including small talk and free-time activity participation) at the event hampered developing relations for novel ideas and eventually innovations. Nevertheless, the participants' opinions differed regarding the 3D digital platform as a trustful and secure site for receiving and sharing useful information for innovation development.

The experiences from the face-to-face world do not transfer straightforward to the virtual world. Such observation requires conceptual elaboration, for example, on the meaning of presence and proximity on virtual platforms. The avatar's role in creating trust and facilitating interaction needs to be studied further. Topics include avatar design practices (such as identification of oneself into it), avatar looks (how colors and clothing impact credibility, visibility and recognition) and avatar's behavior at the event (active/passive, conventional/unconventional). Such studies could help to understand the similarities and differences between the face-to-face practices at physical events and those at the virtual events. People have different skills and characters, and because the avatar is the mediator of interactions, this needs to be scrutinized when thinking about the innovation potential of the virtual platform events. In addition, it would be useful to compare less experienced users of 3D virtual platforms with more experienced users in regard to what they (can) gain from engaging with these digital platforms. It would be especially important to scrutinize how the participants' practices and experiences on the platform impact their innovation potential and what role the platform's digital layout and features (immersiveness) have on it [8]. In the end, users' perspectives are important to know if and how knowledge develops concretely into novel ideas at these digital events, and whether these novel ideas can be developed further towards innovation on virtual platforms. One of the academic contributions of this article- besides the intensive study with detailed empirical results as discussed above-is the conceptual model (see Figure 1) of how knowledge develops into ideas and further into innovations in the current contexts when blended environments are gaining more presence in innovation processes as the case here illustrates.

This study had its limitations. It was a case study and focused on one 3D platform (VirBELA) and on one type of event (innovation and entrepreneurship), thus the findings may not apply straightforwardly to other 3D platforms, although many 3D platforms share similarities in their technical tools and layout, as do the events (event and conferences of different topics). Furthermore, the case regarded a rather simple 3D virtual platform, which means that the detailed findings might differ from those in HIVEs, especially in those oriented to realistic representations of the environment. In addition, most users had rather limited experience with using 3D virtual platforms in innovation and entrepreneurship events, therefore some of their concerns might be because of such novelty. Nevertheless, most of us will be attending sooner or later our virtual reality event, so the results from the first-time users regard much larger audience than those studied here. Furthermore, before virtual reality technology takes major steps forward, the majority of such events will be organized on other platforms than HIVEs.

The studied event was in the end a kind of digitalized physical event rather than trying to obtain full benefits of blended environments to support the emergence of innovations. This was perhaps because it was the first fully virtual event the organizers managed. However, such was and will be the situation for hundreds of event producers and events during and beyond the pandemic. Despite the focus was on a case study, the results from the first-time users and the simple 3D virtual environments provide a useful reference when 
analyzing the practices of the more advanced users and those in HIVEs to understand better how these influence the innovation potential of events on virtual environments as virtual and blended environments are expected to progress quickly in the 2020s $[7,8]$. Studies from virtual events with less immersive virtual platforms during the COVID-19 pandemic are needed to continue with other studies in the post-pandemic period, including those event using more advanced virtual technologies.

Concrete in-depth insights on the impact of networking and idea creation at virtual events give necessary feedback to organizers of 3D virtual entrepreneurship and innovation events. These organizers need to pay attention to creating a trustful atmosphere and joyful interactions among participants in blended environments in which humans act and cooperate through and with avatars. In particular, guidance to attend is needed and suggestions on how to interact would be useful for the less experienced users. These would rise the innovation potential of virtual 3D entrepreneurship and innovation events. The participants should not feel discouraged because of the small technological simplifications in interaction. Virtual events support sustainability by reducing unnecessary travel, consumption and use of time and other resources. Organized properly, the events can increase the participants' novel ideas toward innovations. Furthermore, innovation opportunities can be expected to grow with the development of highly immersive virtual environments.

Funding: The research was funded by the University of Turku and the Business Finland research project BIIDEA2.

Institutional Review Board Statement: Not applicable.

Informed Consent Statement: Not applicable.

Data Availability Statement: Not available.

Conflicts of Interest: The author declares no conflict of interest. The funders had no role in the design of the study; in the collection, analyses, or interpretation of data; in the writing of the manuscript, or in the decision to publish the results.

\section{References}

1. Galgina, T.; Yang, M. Bringing Nordic Slush to Asia: Entrepreneurial internationalization of an NGO as a social movement. Int. Bus. Rev. 2020, 29, 101749. [CrossRef]

2. Maskell, P.; Bathelt, H.; Malmberg, A. Building global knowledge pipelines: The role of temporary clusters. Eur. Plan. Stud. 2006, 14, 997-1013. [CrossRef]

3. Bathelt, H.; Schuldt, N. Between luminaires and meat grinders: International trade fairs as temporary clusters. Reg. Stud. 2014, 42, 853-868. [CrossRef]

4. International Congress and Conference Association. The Impact of the COVID-19 Pandemic on International Meetings Industry. Survey Report; ICCA: Amsterdam, The Netherlands, 2020.

5. McCann, P.; Vorley, T. (Eds.) Productivity and the Pandemic. Challenges and Insights from Covid-19; Edward Elgar: Cheltenham, UK, 2021.

6. Cook, A.; Kuczer, K. A brave new world with virtual worlds. How virtual worlds are the next evolution in communication and collaboration. Deloitte Insights 2020. Available online: https://www2.deloitte.com/us/en/insights/topics/emergingtechnologies/virtual-world-for-business.html (accessed on 15 January 2021).

7. Hruby, F.; Castellanos, I.; Ressl, R. Cartographic scale in immersive virtual environments. KN J. Cartogr. Geogr. Inf. 2020. [CrossRef]

8. Keil, J.; Edler, D.; Schmitt, T.; Dickmann, F. Creating immersive virtual environments based on open geospatial data and game engines. KN J. Cartogr. Geogr. Inf. 2021, 1-13. [CrossRef]

9. Barral, A. Virtual conferences are the future. Nat. Ecol. Evol. 2020, 4, 666-667. [CrossRef]

10. Porpiglia, F.; Checucci, R.; Autorino, R.; Amparore, D.; Cooperberg, M.; Ficarra, V.; Novara, G. Traditional and virtual congress meetings during the COVID-19 pandemic and the post-COVID-19 era: Is it time to change the paradigm? Eur. Urol. 2020, 78, 301-303. [CrossRef] [PubMed]

11. Klöwer, M.; Hopkins, D.; Allen, M.; Higham, J. An analysis of ways to decarbonize conference travel after COVID-19. Nature 2020, 583, 356-359. [CrossRef] 
12. Greenwald, S.; Kulik, A.; Kunert, A.; Beck, S.; Frohlich, B.; Cobb, S.; Parsons, S.; Newbutt, N. Technology and applications for collaborative learning in virtual reality. In Proceedings of the 12th International Conference on Computer Supported Collaborative Learning (CSCL), Philadelphia, PA, USA, 18-22 June 2017; Drexel University and the University of Philadelphia: Philadelphia, PA, USA, 2017.

13. Elia, G.; Margherita, A.; Passiante, G. Digital entrepreneurship ecosystem: How digital technologies and collective intelligence are reshaping the entrepreneurial process. Technol. Forecast. Soc. Chang. 2020, 150, 119791. [CrossRef]

14. Dovey, K. The role of trust in innovation. Learn. Organ. 2009, 16, 311-325. [CrossRef]

15. Hardwick, J.; Anderson, A.; Cruickshank, D. Trust formation processes in innovative collaborations: Networking as knowledge building practices. Eur. J. Innov. Manag. 2013, 16, 4-21. [CrossRef]

16. Kohler, T.; Fueller, J.; Matzler, K.; Stieger, D. Co-creation in virtual worlds: The design of the user experience. Manag. Inf. Syst. Q. 2011, 35, 773-788. [CrossRef]

17. VirBELA. Virbela: A Virtual World for Work, Education \& Events. 2020. Available online: https://www.virbela.com/ (accessed on 15 November 2020).

18. SHIFT. SHIFT Business Webstival. 2020. Available online: https://theshift.fi/speakers-2020/2020 (accessed on 15 November 2020).

19. Lehtiniitty, M. Kasvuyritystapahtuma SHIFT Järjestetään Tällä Viikolla 3D-Virtuaaliympäristössä. [In Finnish, The Growth Enterprise Event SHIFT Will Be Organized This Week in 3D Virtual Environment]. Mobiili.fi, 26 October 2020. Available online: https:/ / mobiili.fi / 2020/10/26/kasvuyritystapahtuma-shift-jarjestetaan-talla-viikolla-3d-virtuaaliymparistossa/ accessed on 15 November 2020).

20. Bourgeois-Bourgine, S.; Richard, P.; Burkhardt, J.; Frantz, B.; Lubart, T. The expression of users' creative potential in virtual and real environments: An exploratory study. Creat. Res. J. 2020, 32, 55-65. [CrossRef]

21. Steinicke, F.; Lehmann-Willenbrock, N.; Meinecke, A.L. A first pilot study to compare virtual group meetings using video conferences and (immersive) virtual reality. In SUI '20: Symposium on Spatial User Interaction; Association for Computer Machinery: New York, NY, USA, 2020; Article 19; pp. 1-2.

22. Hung, S.; Cheng, M.; Hou, C.; Chen, N. Inclusion in global virtual teams: Exploring non-spatial proximity and knowledge sharing on innovation. J. Bus. Res. 2021, 128, 599-610. [CrossRef]

23. Dosi, G. The contribution of economic theory to the understanding of a knowledge-based economy. In The Economic Impact of Knowledge; Siesfeld, T., Cefola, J., Neef, D., Eds.; Elsevier: Amsterdam, The Netherlands, 1998; pp. 123-129.

24. Erkut, B. Product innovation and market shaping: Bridging the gap with cognitive evolutionary economics. Indraprastha J. Manag. 2016, 4, 3-24.

25. Ford, K.; Bradshaw, J.; Adams-Webber, J. Knowledge acquisition as a constructive modeling activity. Int. J. Intell. Syst. 1993, 8 , 9-32. [CrossRef]

26. Men, C.; Luo, J.; Fong, P.; Zhong, J.; Huo, W. Translating external knowledge to team creativity in turbulent environments: The role of absorptive capacity and knowledge integration. J. Creat. Behav. 2020, 54, 363-377. [CrossRef]

27. Plucker, J.; Beghetto, R.; Dow, G. Why isn't creativity more important to educational psychologists? Potentials, pitfalls, and future directions in creativity research. Educ. Psychol. 2004, 39, 83-96. [CrossRef]

28. Nilsson, M. Proximity and the trust formation process. Eur. Plan. Stud. 2019, 27, 841-861. [CrossRef]

29. Breuer, C.; Hüffmeier, J.; Hibben, F.; Hertel, G. Trust in teams: A taxonomy of perceived trustworthiness factors and risk-taking behaviors in face-to-face and virtual teams. Hum. Relat. 2020, 73, 3-34. [CrossRef]

30. Hautala, J.; Jauhiainen, J. Spatio-temporal aspects of knowledge creation. Res. Policy 2014, 43, 655-668. [CrossRef]

31. Boschma, R. Proximity and innovation: A critical assessment. Reg. Stud. 2005, 39, 61-74. [CrossRef]

32. Storper, M.; Venables, A. Buzz. Face-to-face contact and the urban economy. J. Econ. Geogr. 2004, 4, 351-370. [CrossRef]

33. Parjanen, S.; Hella, L.; Konsti-Laakso, S. Brokerage functions in a virtual idea generation platform: Possibilities for collective creativity? Innovation 2012, 14, 363-374. [CrossRef]

34. Bjork, S.; Holopainen, J. Patterns in Game Design; Charles River Media: London, UK, 2004.

35. Dupont, L.; Pallot, M.; Morel, L. Exploring the appropriateness of different immersive environments in the context of an innovation process for smart cities. In Proceedings of the 22nd ICE/IEEE International Technology Management Conference, Trondheim, Norway, 13-15 June 2016.

36. Hernández, R.; Cooper, R.; Tether, B.; Murphy, E. Design, the language of innovation: A review of the design studies literature. She Ji J. Des. Econ. Innov. 2018, 4, 249-274. [CrossRef]

37. Kohler, T.; Matzler, K.; Füller, J. Avatar-based innovation: Using virtual worlds for real-world innovation. Technovation 2009, 29, 395-407. [CrossRef]

38. Choudhury, P. Our work from anywhere future. Harv. Bus. Rev. 2020.

39. Nilsson, M.; Mattes, J. The spatiality of trust: Factors influencing the creation of trust and the role of face-to-face contacts. Eur. Manag. J. 2015, 33, 230-244. [CrossRef]

40. Bailenson, J.; Beall, A. Transformed social interaction: Exploring the digital plasticity of avatars. In Avatars at Work and Play: Collaboration and Interaction at Virtual Environments; Schroeder, R., Axelsson, A., Eds.; Springer: Berlin, Germany, 2006.

41. Berger, M.; Jucker, A.H.; Locher, M.A. Interaction and space in the virtual world of Second Life. J. Pragmat. 2016, 101, 83-100. [CrossRef] 
42. Latoschik, M.; Roth, D.; Gall, D.; Achenbach, J.; Waltemate, T.; Botsch, M. The effect of avatar realism in immersive social virtual realities. In Proceedings of the VRST' 17: 23rd ACM Symposium on Virtual Reality Software and Technology, Gothenburg, Sweden, 8-10 November 2017; Association for Computer Machinery: New York, NY, USA, 2017. Article No. 39. pp. 1-10.

43. Suh, K.; Kim, H.; Suh, E. What if your avatar looks like you? Dual-congruity perspectives for avatar use. MIs Q. 2011, 35, 711-729. [CrossRef]

44. Kraus, M.; Mendes, W. Sartorial symbols of social class elicit class-consistent behavioral and physiological responses: A dyadic approach. J. Exp. Psychol. Gen. 2014, 143, 2330-2340. [CrossRef] [PubMed]

45. Messinger, P.; Ge, X.; Smirnov, K.; Stroulia, E.; Lyons, K. Reflections of the extended self: Visual self-representation in avatarmediated environments. J. Bus. Res. 2019, 100, 531-546. [CrossRef]

46. Kruzic, C.O.; Kruzic, D.; Herrera, F.; Bailenson, J. Facial expressions contribute more than body movements to conversational outcomes in avatar-mediated virtual environments. Sci. Rep. 2020, 10, 20626. [CrossRef]

47. Oh, S.; Bailenson, J.; Krämer, N.; Li, B. Let the avatar brighten your smile: Effects of enhancing facial expressions in virtual environments. PLoS ONE 2016, 11, e0161794. [CrossRef] [PubMed]

48. Maritz, A.; Perenyi, A.; de Waal, G.; Buck, C. Entrepreneurship as the unsung hero during the current COVID-19 economic crisis: Australian perspectives. Sustainability 2020, 12, 4612. [CrossRef] 